\title{
Larval supply of coral reef fish populations: magnitude and synchrony of replenishment to Lizard Island, Great Barrier Reef
}

\author{
M. J. Milicich*, P. J. Doherty** \\ School of Environmental Studies, Grififith University, Nathan, Brisbane, Queensland 4111, Australia
}

\begin{abstract}
Larval supply is crucial for the persistence of coral reef fish populations, yet little direct information exists about any aspect of this life history phase. Using light traps, this study directly measured larval supply of 27 coral reef fish taxa to Lizard Island (northern Great Barrier Reef) over 2 successive recruitment seasons. Descriptions of the magnitude and synchrony of replenishment to 3 different habitats (front-reef, back-reef and lagoon) within a single reef are the first of their kind and reveal several important facets of the larval supply process. Larval supply during the first season was much stronger into the front-reef side than into the back-reef habitat. Synchrony of daily replenishment between these 2 habitats was characteristically weak during this year. This result was not related in any simple way to low levels of absolute abundance in the back-reef habitat. In the following year, this dominance of the front-reef habitat was diminished. In many cases, this decline could be explained by a rise in the strength of the replenishment signal in the back-reef habitat. Correlated with this, there was a general increase in the strength of synchrony in larval supply between the 2 habitats. Again this trend could not be simply explained by any increase in absolute abundance in the back-reef habitat. It appears that there was a change in the nature of the larval supply process between these habitats over the 2 years. Although temporally variable, replenishment into either habitat showed consistent patterns across many taxa indicating that larval supply to a single reef is systematic rather than 'stochastic' We suggest that investigation of the relationship between larvae and the local physical conditions surrounding each reef may reveal the reasons for much of this complexity in replenishment. Larval supply into the lagoon was highly variable among taxa. The greater association of the lagoon with the frontreef habitat was revealed by the cross-correlation coefficients of many taxa. In some cases this could be explained by a progressive depletion of larvae as they crossed the front-reef crest and entered the lagoon. However, larval abundance of 4 taxa in the lagoon was so low (seasonal sum < 10 for Pomacentrus coelestus, Lethrinidae, P. lepidogenys and Neopomacentrus spp.) that active behavioural choice of settling larvae seems to be involved.
\end{abstract}

KEY WORDS: Larval supply $\cdot$ Reef fish - Recruitment

\section{INTRODUCTION}

Coral reef fish populations are replenished by an annual supply of larvae that develop in the pelagic environment before settling into benthic habitats. The magnitude of settlement (or year-class formation) has been shown to vary widely across a range of temporal

Present addresses:

- Dept Marine Biology, James Cook University, Townsville,

Queensland 4811, Australia

- Australian Institute of Marine Science, Townsville, Queensland 4811, Australia and spatial scales (see review in Doherty \& Williams 1988 ) and the persistence of signals up to $10 \mathrm{yr}$ later demonstrates that settlement is a major force structuring these populations (Doherty \& Fowler 1993).

The raw material of settlement is the supply of competent larvae, however the act of settling forces young fish to pass through a sequence of interactions (among colonisers, and between colonisers, their environment and other reef residents; Sweatman 1985, Jones 1987, Booth 1992) that distort the initial larval signal. To understand variations in the magnitude of settlement, reef effects must be separated from the process of larval replenishment. Directly measuring larval supply 
accomplishes this objective (Doherty 1987a, Milicich 1988, Milicich et al. 1992, Shenker et al. 1993) and, perhaps more importantly, focuses research on a phase of the life history of coral reef fishes that has received scant attention in the past. This focal shift may be crucial since almost a century of fisheries research suggests that growth, mortality and advection during the larval phase are major factors influencing the dynamics of many northern temperate fish populations (Rothschild 1986).

The magnitude and timing of larval supply are determined by events occurring at (1) the time of spawning, (2) as larvae disperse and develop within the pelagic environment and/or (3) as larvae approach reef habitats. Reasonably strong lunar signals in the timing of replenishment (tied to the new moon) have been related to spawning rhythms (Meekan et al. 1993, Milicich unpubl.). However, lack of a convincing relationship between levcls of spawning output and iarval supply or settlement to the same reef suggest that the magnitude of replenishment may be primarily determined while fish are in their pelagic phase (Robertson et al. 1988, Meekan et al. 1993). A major limitation of this approach is the failure to measure reproduction at the spatial scale at which the larvae are likely to mix, disperse and then replenish reefs. As this scale remains unknown for any reef fish, the true level of spawning output has yet to be determined. However, even where the boundaries of the stock are quite well known, as in some commercial fisheries, the relationship between the magnitude of spawning output and the size of subsequent recruitment events has been less than convincing and predictive (Cushing 1982, Daan et al. 1990). In addition, recent work suggests that the spawning and larval supply processes have very different dynamics, an unlikely result if the magnitude of one strongly influences the magnitude of the other (Milicich \& Sugihara unpubl.).

Processes affecting larvae may be physical (e.g. El Niño events, wind stress), biological (e.g. competition for food, predation, behaviourj or, more realistically, a complex combination of both (e.g. interaction of turbulence with food supply, interaction of behaviour with vertical distribution; Lasker 1981, Cushing 1982, Leis 1991). Studies such as those cited above typically focused on early larval stages that are successfully sampled using conventional techniques such as towed nets. The high mobility and sensory competence of older larvae allows them to detect and avoid nets (Choat et al. 1993) and as a consequence little information about this life history stage has been available. This gap in understanding is significant since the nature and scale of processes affecting larvae may be expected to change ontogenetically. In coral reef fishes, for example, the interaction of older settlement- stage larvae with local conditions surrounding each reef may be as significant in determining the final magnitude of larval supply as processes affecting younger larvae.

Light traps have been used as a tool for sampling the older larval forms of coral reef fishes since Doherty (1987a) adapted a Faber (1981) freshwater trap design for use in the marine environment. Rigorous comparison of samples taken simultaneously with light traps and towed nets leave little doubt that light traps are the favoured gear for sampling older larvae (Choat et al. 1993). Documentation of a clear relationship between catches in light traps moored around a reef and concurrent measures of settlement to the reef suggest that light traps are a reliable measure of larval supply (Milicich et al. 1992). Clearly the gear is selective and is only useful for those taxa that respond to light, however the range of taxa successfully sampled using this technique is wide and includes species for which there was little or no prior information about the larval or newly settled stage.

Using light traps, the major aim of this study is to describe the magnitude of larval supply to 3 habitats at Lizard Island, a continental island with a fringing reef and a lagoon, situated in the northern area of the Great Barrier Reef (GBR). Replenishment on the GBR is seasonal (Doherty \& Williams 1988), and centred around the summer months (October to January at Lizard Island); data collected here come from 2 consecutive seasons. As traps are fully automated, replenishment can be mapped synoptically at a range of spatial scales. Describing the distribution patterns of larvae simultaneously for many taxa should give unique insight into processes that operate as larvae approach benthic habitats. Identification of trends in overall magnitude along with more focused analysis of daily supply events may reveal facets of replenishment that range from macro-scale changes in the nature of larval supply to the taxon-specific behaviour of individual larvae.

Specific questions addressed were as follows: (1) How does the magnitude of larval supply vary on a single reef, among habitats and does this pattern change between recruitment seasons? (2) Are larval supply events on a daily scale synchronous among habitats and does this change across years?

\section{METHODS}

Sampling. As the spatial coverage of the sampling design differed between the 2 consecutive seasons $(1987-88,1988-89)$ of sampling, the questions posed in this paper were addressed using specific parts of the total database. Although most taxa could be identified 
to the species level ( $74 \%$ ) lack of previous samples for some taxa meant that identification to the species level was often not definitive at the start of the study. As a result, replenishment patterns in this contribution are variously reported at the species, genus or family level. Taxa recorded as a genus name followed by 'sp.' refer to distinct morphs that could not be reliably matched with a known specific name. The category 'small pomacentrids' refers to post-flexion pomacentrids that were not yet competent to settle (on average $<8 \mathrm{~mm}$ SL). Schooling pelagics collected in the light traps were of mixed ages and included the families Clupeidae and Atherinidae. Taxa were analysed if they occurred in the samples with sufficient frequency for sensible analysis. This level was not fixed but was determined from perusal of the time-series on a case by case basis. Taxa were not excluded for any other reason. A significance level of $95 \%$ was used in every analysis.

The operation and design of the light traps has been described in detail elsewhere (Doherty 1987a, Milicich 1988, Thorrold \& Milicich 1990, Milicich et al. 1992). Briefly, traps were suspended from the surface and secured to a permanent mooring. Three fishing periods were set throughout the night: 21:00-22:00, 24:00-01:00 and 03:00-04:00 h. These staggered $1 \mathrm{~h}$ periods minimised effects of time of night or tidal state. Traps were cleared daily and all larvae that could be immediately identified were preserved, while unidentified species were maintained in aquaria until further pigmented.

Inter-habitat comparisons. In the 1987-88 season, 3 traps were deployed in both the front-reef and back-reef habitats (Fig. 1). The back-reef bay was larger and shallower than the front-reef site; traps were spread further apart across the bay and stationed slightly further from the reef for the 2 southernmost positions. For the second season, 2 traps were deployed in each of 3 habitats: front-reef, back-reef and the lagoon (Fig. 1). As for the previous year, front-reef traps were deployed near the reef margin, while the back-reef traps were set between the 3 positions sampled in the previous year. Lagoon traps were deployed at a position close to the front-reef margin and at a site deeper within the lagoon. These traps were the last to be deployed and consequently the time-series for these catches were shorter than for traps in the other habitats. In addition, for half of the sampling period, only a single trap was operational within the lagoon habitat. While this lack of replication is a problem, evidence from other work indicates that time-series of catches show strong coherence among adjacent traps (Milicich 1992, Milicich et al. 1992). For this reason, single trap collections were considered a good representative of the major patterns in larval supply. This sampling design allowed patterns in the magnitude and synchrony of catches among habitats to be investigated for up to 3 habitats within a season, and inter-annual variations to be investigated between the front-reef and back-reef habitats.

Overall comparison of magnitude: The abundance of pre-settlement fish of 27 taxa was compared among habitats and across the 2 sampling seasons. Daily catches from individual traps were averaged within habitats and then integrated to produce a single seasonal total for each habitat. Occasionally a trap failed in a given habitat and when this occurred the record from the remaining trap was used to represent larval supply for that day (see Milicich et al. 1992). Traps were suspected to have failed when there was no fish and no planktonic component in the trap. On these occasions failure was confirmed or denied by testing the lights inside the trap. Of more significance were the rare occasions when all traps in a given habitat failed to operate. Calculation of seasonal totals was based only on those sampling days where records existed from all the habitats concerned.

A paired-sample $t$-test using species as samples and habitats as variables was calculated to determine if

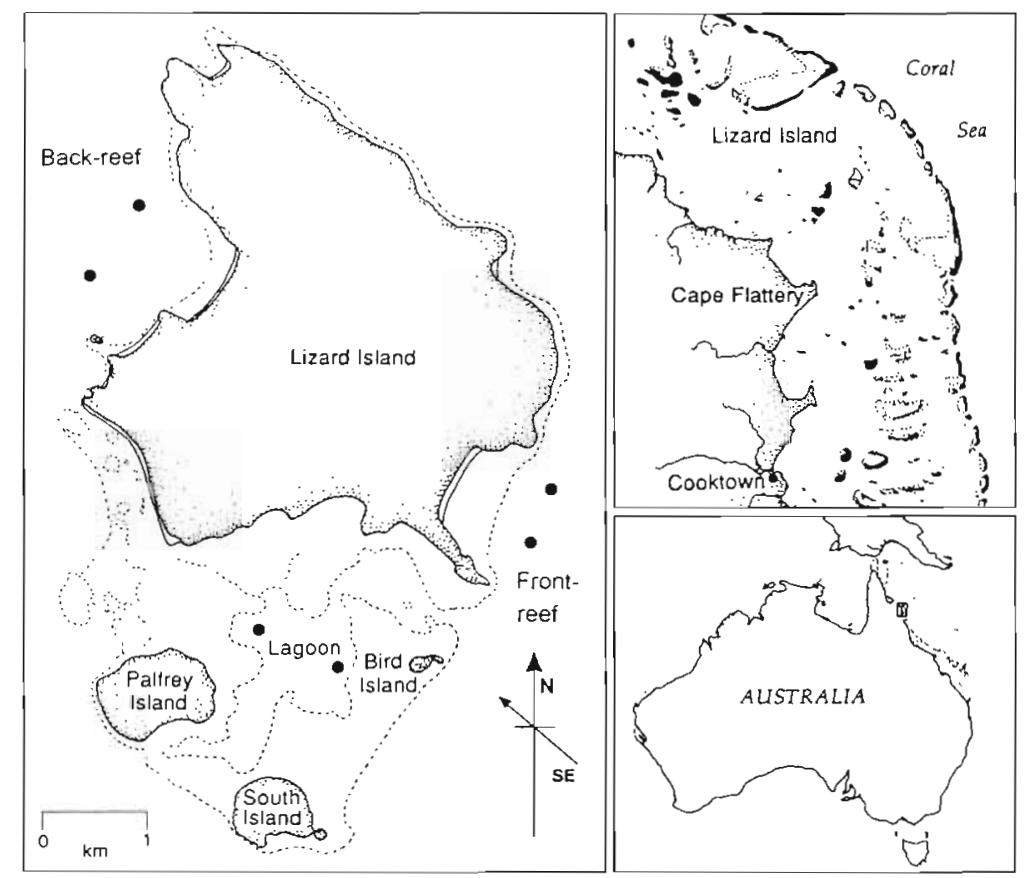

Fig. 1. Locations of sampling sites, Lizard Island, Great Barrier Reef 
there were any general differences in the magnitude of larval supply between the front-reef and back-reef habitats. A separate test was conducted for each season. A log-likelihood ratio test was calculated to determine if the proportion of larvae supplying the frontreef and back-reef habitats differed between the 2 seasons. The inclusion of the lagoon habitat in the second season allowed larval supply in all 3 habitats to be compared simultaneously using a randomized block ANOVA with individual taxa as blocks. This was followed by a series of chi-square goodness-of-fit tests that determined whether larval supply of individual taxa was evenly split among the 3 habitats.

Daily comparisons of magnitude: Changes in the daily magnitude of larval replenishment among habitats were investigated by evaluating the degree of synchrony in larval supply. This was accomplished by calculating pair-wise cross-correlations of time series (Milicich et al. 1992) between the front-reef and backreef habitats for 20 taxa that were common enough in both seasons of sampling to allow profitable analysis With the addition of the lagoon to the final year of sampling, 4 more taxa were included in the analysis. Missing trap records were dealt with in the same way as for the overall comparison of magnitude. The presence of autocorrelation in the data was assessed by inspecting the autocorrelation (ACF) plot. Short-term autocorrelations were removed from the data using autoregressive (AR) models (Mesosaur-Systat; Kuznetsov \& Khalileev 1991). The appropriateness and strength of the model were assessed using a range of 'information parameters' such as the Portmanteau test, $t$-tests on the model's parameters, Durban-Watson statistic for residual analysis, chi-square white noise test, and finally the graphical form of both the integrated periodogram and the residuals.

\section{RESULTS}

\section{Comparison of magnitude}

Over all taxa, the magnitude of larval supply during the first season differed between the front-reef and back-reef habitats $(p=0.03, d f=26)$. Fig. 2 reveals that more larvae were captured off the front-reef side; for $70 \%$ of the taxa, catches in the back-reef habitat accounted for a mean proportion of only $20.7 \% \pm 1.9$ SE (range 2 to $35 \%$ ) of the total catch. However, in the following year this prevalence of the front-reef habitat had diminished sufficiently to prevent detection of any overall dominance of one habitat over another ( $p=$ 0.06, df $=26$ ).

Results of the log-likelihood ratio tests performed on individual taxa indicate that in $63 \%$ of cases this change could be explained by a significant proportional increase in the size of the back-reef catch (mean percent increase: $22.8 \pm 3.1 \mathrm{SE}$, range 4.6 to $53.6 \%$ ) (Fig. 2). For the first 17 taxa listed in Fig. 2, the increase was between 15 and $54 \%$, although for 3 of these (Ecsenius sp., lethrinids and small pomacentrids) the proportional abundance in the back-reef habitat was still low. Larval supply into the back-reef habitat did not increase proportionately between seasons for 8 of the remaining 10 taxa. As can be seen from Fig. 2, larval supply in at least 5 of these taxa (Pomacentrus lepidogenys, Amblypomacentrus breviceps, Apogon sp1, Chromis atripectoralis and Abudefduf vaigiensis) appeared to be consistently higher into the front-reef habitat in both seasons. In 2 further taxa, the pomacentrids Chrysiptera rolandi and $P$. coelestis, the strength of the dominance of the front-reef side significantly increased between the 2 seasons. Carangids appeared to be the sole taxa that were consistently more abundant in light traps deployed on the back-reef side of Lizard Island. There appeared to be no clear-cut distinction in the patterns discussed above in relation to taxonomic groupings. Thus, each pattern described above had representatives of a wide taxonomic range of fish including non-reef species.

Decrease in the dominance of the front-reef habitat between years could occur by chance if overall abundance levels declined sufficiently to prevent the successful detection of pattern. The bold numbers in Fig. 2 represent greater than 2 -fold changes in abundance of individual taxa between years and all, bar one (lethrinids), consisted of an increase in absolute abundance from the first to the second season. Despite the strong decline in abundance of the lethrinid larvae, the split in larval supply between the habitats was far from even, a result opposite to that expected if the resolving power of the light traps had seriously weakened. Although the relative increase in larval abundance in the back-reef habitat appears to be a real phenomenon, it may not mean that the absolute abundance of fish increased in this habitat between years. A similar result would occur, for instance, if the absolute abundance of supply into the front-reef habitat declined. The last 2 columns of Fig. 2 show that this latter is not the case. There was a proportional increase in replenishment into the back-reef habitat across the years for 23 of the 27 taxa, and for $78 \%$ of these the increase was greater than $50 \%$. Additionally, the magnitude of larval supply into the front-reef habitat declined for only one-third of taxa (range 7 to $88 \%$ ).

When the lagoon habitat was added to the comparison during the second season, a randomized block ANOVA (blocking among taxa) failed to detect any general consistent difference in larval supply among the 3 habitats $(p>>0.25$, df $=2,53$ ). The results of all 


\begin{tabular}{|c|c|c|c|c|c|c|}
\hline \multirow[t]{2}{*}{ Taxa } & \multicolumn{2}{|c|}{ \% by habitat } & \multicolumn{3}{|c|}{ Total larval supply } & \\
\hline & Year 1 Year 3 & G-test & Year 1 & Year 2 & $\begin{array}{c}\% \text { change } \\
\text { Front-reef Back-reef }\end{array}$ & \\
\hline Pomacentrus tripunctatus & & $p<<0.001$ & 223.5 & 567.0 & $\circ$ & \\
\hline Apogonsp 2 & & $p<<0.001$ & 41.5 & 160.5 & & \\
\hline Other blenniids & & $p<<0.001$ & 136.7 & 123.5 & 0 & \\
\hline Other apogonids & & $p<<0.001$ & 201.0 & 129.0 & 0 & \\
\hline Eviotasp. & & $0.025<p<0.05$ & 52.9 & 133.5 & & \\
\hline Meiacanthus sp. & & $p<0.001$ & 102.7 & 199.0 & & \\
\hline P. amboinensis & & $p<<0.001$ & 1106.5 & 1056.0 & 0 & \\
\hline Dischistodus spp. & & $p<<0.001$ & 166.6 & 2355.0 & & \\
\hline P. moluccensis & & $p<<0.001$ & 401.6 & 1139.5 & & \\
\hline P. chrysurus & & $0.001<p<0.005$ & 89.5 & 336.5 & & \\
\hline P. brachialis & & $p<0.001$ & 125.8 & 562.5 & & \\
\hline Schooling pelagics & & $p<<0.001$ & 5357.5 & 3258.0 & 0 & \\
\hline Neopomacentrusspp. & & $p<0.001$ & 159.1 & 274.5 & - & \\
\hline Lethrinidae & & $p<<0.001$ & 2931.1 & 416.0 & & \\
\hline Ecsenius sp. & & $p<<0.001$ & 149.2 & 264.5 & $\bullet$ & \\
\hline P. nagasakiensis & & $0.025<p<0.05$ & 413.5 & 395.5 & 。 & \\
\hline Small pomacentrids & & $0.025<p<0.05$ & 237.7 & 1013.0 & & \\
\hline P. wardi & & ns & 35.4 & 408.0 & & \\
\hline P. lepidogenys & & ns & 40.7 & 462.5 & & \\
\hline Syngnathidae & & ns & 70.8 & 47.5 & 0 & \\
\hline Amblypomacentrus breviceps & & ns & 41.2 & 205.5 & & \\
\hline Apogonsp 1 & & ns & 132.3 & 395.5 & 0 & \\
\hline Chromis atripectoralis & & ns & 350.8 & 314.5 & . & \\
\hline Abudefduf vaigiensis & & ns & 45.4 & 73.5 & - & \\
\hline Chrysiptera rolandi & & $0.01<p<0.025$ & 692.8 & 764.5 & - & \\
\hline P. coelestus & & $0.001<p<0.005$ & 396.1 & 473.0 & & SCALE \\
\hline Carangidae & & ns & 32.7 & 78.0 & & $25 \%$ \\
\hline
\end{tabular}

Fig. 2. Comparison of larvae supplying the front-reef and back-reef habitats over 2 consecutive seasons for 27 taxa. Pie charts show percentage contribution of annual replenishment by habitat (black: front-reef; white: back-reef). Circles show percentage change (filled circles: increase; open circles: decrease) in larval supply for each habitat. G-test: significance of proportional changes by year in the contribution of each habitat to total larval supply. ns: non-significant ( $95 \%$ level). Bold abundance values: 


\begin{tabular}{|c|c|c|}
\hline Taxa & $\begin{array}{l}\% \text { by } \\
\text { habitat }\end{array}$ & $\begin{array}{c}\text { Goodness- } \\
\text { of-fit }\end{array}$ \\
\hline Pomacentrus coelestus & & $p<<0.001$ \\
\hline Lethrinidae & & $p<<0.001$ \\
\hline P. lepidogenys & & $p<<0.001$ \\
\hline Neopomacentrus spp. & & $p<<0.001$ \\
\hline$P$. nagasakiensis & & $p<<0.001$ \\
\hline P. brachialis & & $p<<0.001$ \\
\hline Carangidae & & $p<<0.001$ \\
\hline Chrysiptera rollandi & & $p<<0.001$ \\
\hline P. chrysurus & & $p<<0.001$ \\
\hline Abudefduf vaigiensis & & $p<<0.001$ \\
\hline Meiacanthus sp. & & $p<<0.001$ \\
\hline Ecsenius sp. & & $p<<0.001$ \\
\hline Amblypomacentrus breviceps & & $p<<0.001$ \\
\hline Apogon sp 1 & & $p<<0.001$ \\
\hline Other blenniids & & $p<<0.001$ \\
\hline Chromis atripectoralis & & $p<<0.001$ \\
\hline P. wardi & & $p<<0.001$ \\
\hline P. tripunctatus & & $p<<0.001$ \\
\hline Syngnathidae & & ns \\
\hline P. moluccensis & & $p<<0.001$ \\
\hline Other apogonids & & ns \\
\hline Dischistodus spp. & & $p<<0.001$ \\
\hline Small pomacentrids & & $p<<0.001$ \\
\hline P. amboinensis & & $p<<0.001$ \\
\hline Apogon sp 2 & & $p<<0.001$ \\
\hline Eviotasp. & & $p<<0.001$ \\
\hline Schooling pelagics & & $p<<0.001$ \\
\hline
\end{tabular}

Fig. 3. Comparison of larvae supplying the front-reef, backreef and lagoon habitats during the 2 nd recruitment season for 27 taxa. Pie charts show percentage contribution of annual replenishment by habitat (black: front-reef; white: back-reef; shaded: lagoon). Goodness-of-fit tests whether larvae supplied all habitats evenly; ns: non-significant but 2 of the individual goodness-of-fit tests show that this did not mean that larval supply was uniform among habitats (Fig. 2). Rather, replenishment into the lagoon habitat appeared to be far more variable among taxa than supply into either the front-or the back-reef habitats (coefficients of variation: $0.87,0.39,0.52$ ) and this probably accounted for the lack of significance in the ANOVA. This complexity can be best summarised by considering, for each taxon, both the proportion and absolute abundance of total replenishment that occurred in the lagoon habitat.

Larval supply into the lagoon accounted for less than $22 \%$ of the total catch in $70 \%$ of cases (first 19 taxa in Fig. 3). This pattern may reflect a consistent tendency for larvae to be rarer in the lagoon or it could simply arise as a by-product of larvae being more abundant elsewhere. To distinguish between these 2 alternatives, we separate these taxa according to a further criierion; if larvae occur in the lagoon at less than half the abundance than in either of the other 2 habitats we interpret this as evidence for a negative bias in the supply of larvae to the lagoon. This criterion was met by the first 10 taxa in Fig. 3. In addition, for the îrst 4 of these (Pomacentrus coelestus, Lethrinidae, P. lepidogenys and Neopomacentrus spp.) larval abundance in the lagoon was so low that the sum value calculated for the entire season was never more than 10 .

Larval supply of 2 taxa, the syngnathids and members of the 'other apogonid' category, was distributed evenly among all 3 habitats. Of the 7 remaining taxa, lagoon replenishment of 6 ranged from 40 to $80 \%$ of the total seasonal supply. Three of these, Apogon sp2, Eviota sp. and the schooling pelagics showed a clear preference for the lagoon over either the front-reef or the back-reef habitats. Small pomacentrid larvae were distributed relatively evenly between the front-reef and lagoon habitats, however they were consistently rarer in back-reef traps (Fig. 2). A similar though not so striking pattern was shown by larval supply of Pomacentrus amboinensis, P. moluccensis and Dischistodus spp. Larval replenishment of these taxa proportionally increased into the back-reef habitat between the first and second seasons (Fig. 2), however the front-reef and lagoon habitats still received most of the incoming larvae. Similar to the front-reef and back-reef comparison, there were no clear taxonomic relationships in the pattern of larval supply into the lagoon habitat.

\section{Comparison of synchrony}

Synchrony in the catches of pre-settlement fish between the front-reef and back-reef habitats during the first sampling season is summarised in Fig. 4 for the 20 taxa analysed. Significant synchrony was detected 


\begin{tabular}{|c|c|c|c|c|c|c|c|}
\hline \multirow[t]{2}{*}{ Taxa } & \multicolumn{2}{|c|}{ Front-reef/back-reef } & \multirow{2}{*}{$\begin{array}{l}\text { Change in } \\
\text { synchrony }\end{array}$} & \multirow{2}{*}{$\begin{array}{c}\begin{array}{c}\text { Front-reef/ } \\
\text { lagoon } \\
\text { Year } 2\end{array}\end{array}$} & \multirow{2}{*}{$\begin{array}{l}\text { Back-reef/ } \\
\text { lagoon } \\
\text { Year } 2\end{array}$} & \multirow[t]{2}{*}{ Difference } & \\
\hline & Year 1 & Year 2 & & & & & \\
\hline P. nagasakiensis & 0.44 & 0.26 & 0 & & & & \\
\hline P. moluccensis & 0.43 & 0.66 & 0 & 0.92 & 0.67 & & \\
\hline Schooling pelagics & 0.41 & 0.30 & $\circ$ & 0.48 & 0.30 & & \\
\hline P. brachialis & 0.32 & 0.54 & $\bullet$ & & & & \\
\hline C. atripectoralis & 0.28 & 0.41 & $\bullet$ & 0.65 & 0.28 & & \\
\hline Meiacanthus spp. & 0.27 & 0.32 & $\cdot$ & $0.19(\mathrm{~ns})$ & $0.16(\mathrm{~ns})$ & & \\
\hline Syngnathidae & 0.24 & 0.86 & & 0.55 & 0.65 & O & \\
\hline Other apogonids & 0.23 & 0.43 & - & 0.75 & 0.30 & & \\
\hline Neopomacentrus spp. & 0.22 & 0.00 & 0 & & & & \\
\hline A. breviceps & $0.27(3)$ & 0.00 & 0 & 0.09 (ns) & 0.06 (ns) & $\bullet$ & \\
\hline Dischistodus spp. & $0.34(5)$ & 0.65 & & 0.59 & 0.60 & $\circ$ & \\
\hline P. coelestis & $0.29(5)$ & 0.26 & & & & & \\
\hline$P$. tripunctatus & 0.12 (ns) & 0.88 & & 0.30 & 0.40 & 0 & \\
\hline P. chrysurus & 0.14 (ns) & 0.71 & & 0.76 & 0.48 & & \\
\hline P. lepidogenys & -0.05 (ns) & 0.80 & & & & & \\
\hline A. vaigiensis & -0.17 (ns) & $0.17(\mathrm{~ns})$ & & 0.33 & $-0.05(\mathrm{~ns})$ & & \\
\hline Ecsenius sp. & $0.09(\mathrm{~ns})$ & 0.34 & 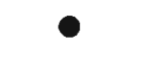 & & & & \\
\hline Other blenniids & 0.05 (ns) & 0.35 & 0 & 0.47 & 0.04 (ns) & & \\
\hline Apogon sp 1 & 0.11 (ns) & 0.40 & 0 & 0.54 & 0.38 & & \\
\hline C. rollandi & 0.18 (ns) & 0.25 & - & 0.49 & 0.35 & & \\
\hline P. wardi & & 0.53 & & 0.29 & -0.10 & & \\
\hline P. amboinensis & & 0.24 & & 0.92 & 0.41 & & \\
\hline Eviota sp. & & 0.05 (ns) & & -0.05 (ns) & $0.52(3)$ & & $100 \%$ \\
\hline Apogon sp 2 & & 0.61 & & 0.44 & 0.35 & & $25 \%$ \\
\hline
\end{tabular}

Fig. 4. Comparison (correlation coefficients) of the inter-habitat synchrony in larval supply among 24 taxa. Circles represent percentage difference (filled circles: positive; open circles: negative) in synchrony between years for front-reef/back-reef and between front-reef/lagoon and back-reef/lagoon for the second season. Numbers in brackets identify lag values $>2 ; n s$ : nonsignificant ( $95 \%$ level). Genus names given in full in Fig. 3

for less than half (8) of the taxa at lags of 0 to $2 \mathrm{~d}$, and even in these cases, the correlation coefficients were not strong (Figs. 4 \& 5a to e). For 3 of the remaining taxa, a significant cross-correlation was detected with lags of 3 to $5 \mathrm{~d}$, although again the strength of the concordance was relatively low. For Dischistodus sp. and Amblypomacentrus breviceps, this delay effect could be explained by a lag in the appearance of fish in the back-reef habitat during the October new moon (e.g. Fig. 5a). For Pomacentrus coelestis, the phase-shift appeared to be consistent across 3 new moon pulses, and appeared to be driven by an absence of fish from the back-reef habitats during the latter days of a given pulse event (Fig. 5b).

Low coherence values, even where significant, may simply result from the often low numbers of fish that 
a

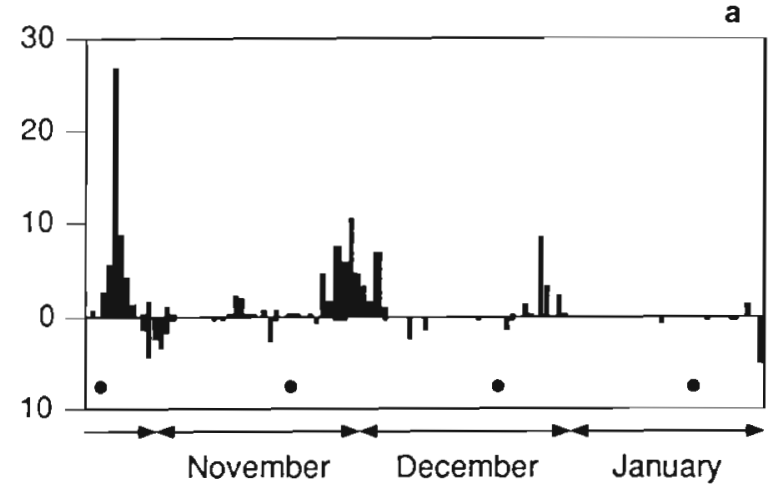

C
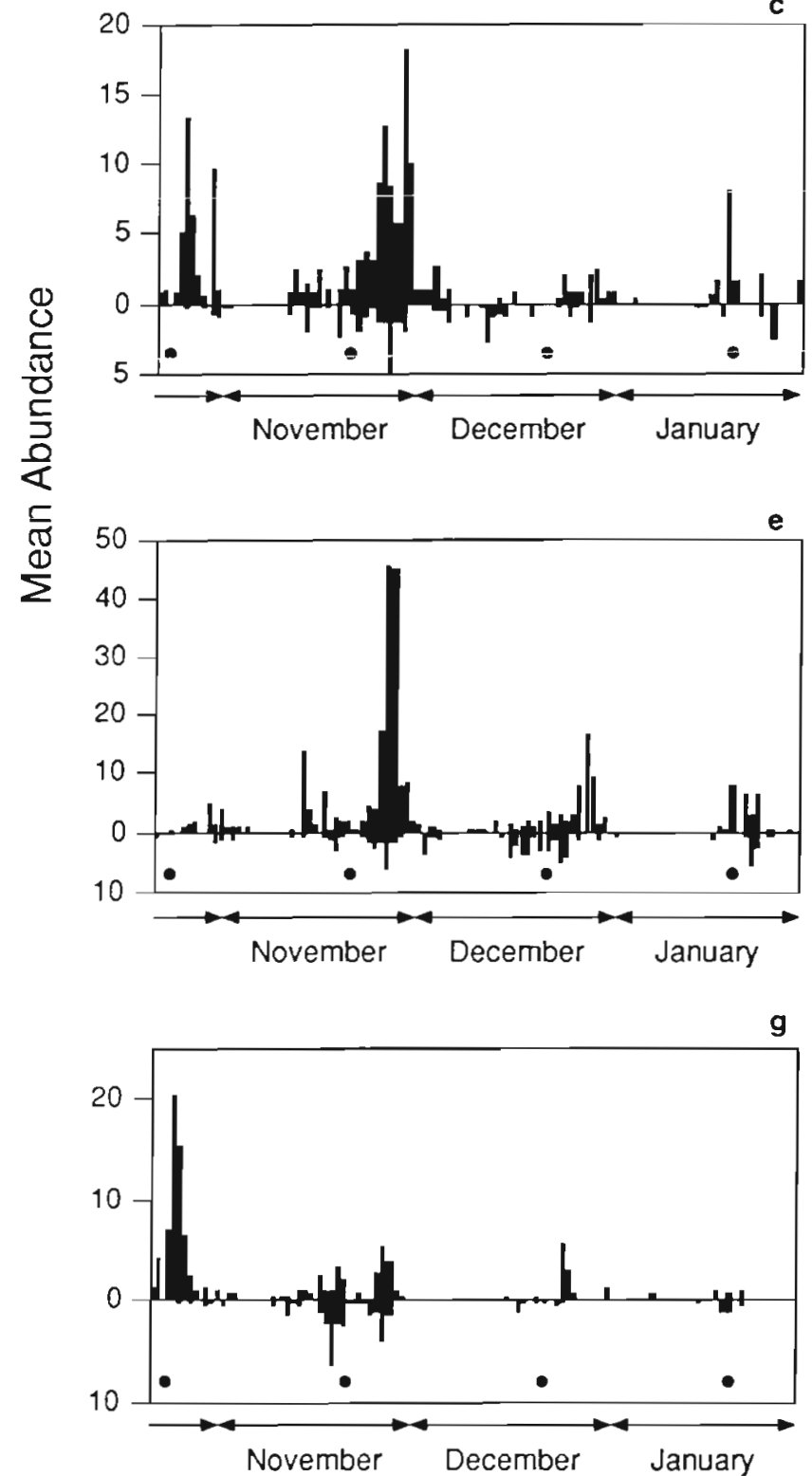

b

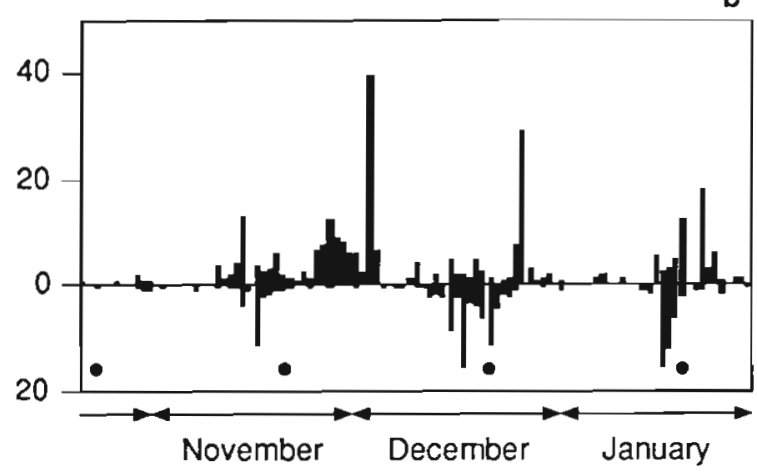

d
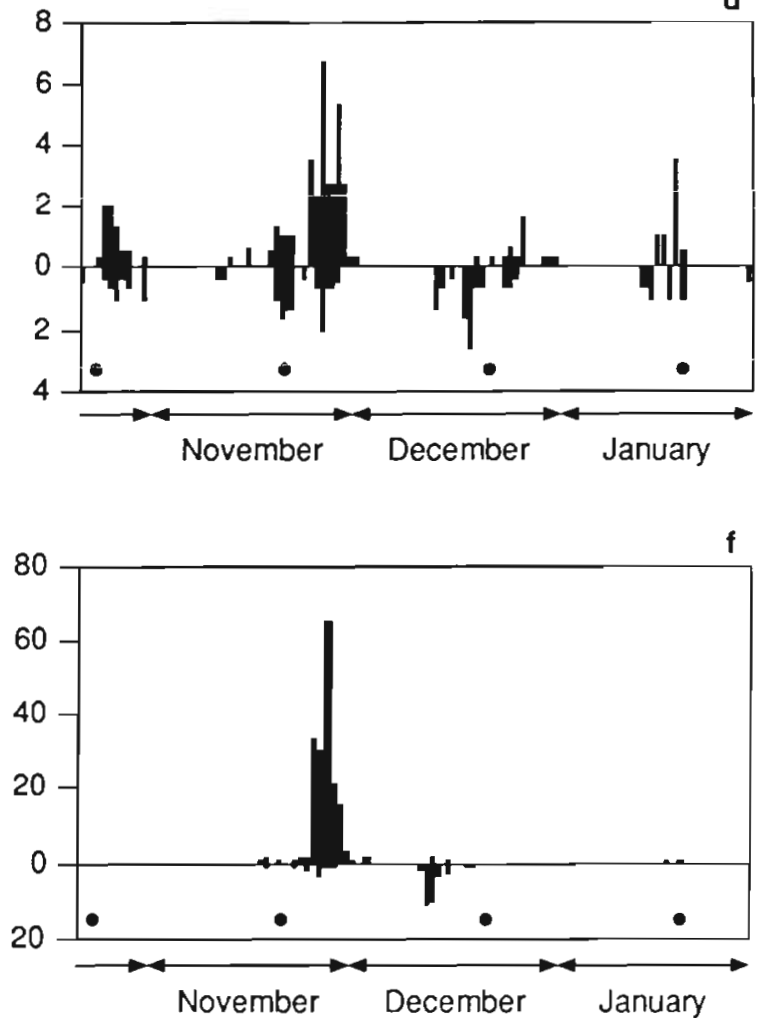

h

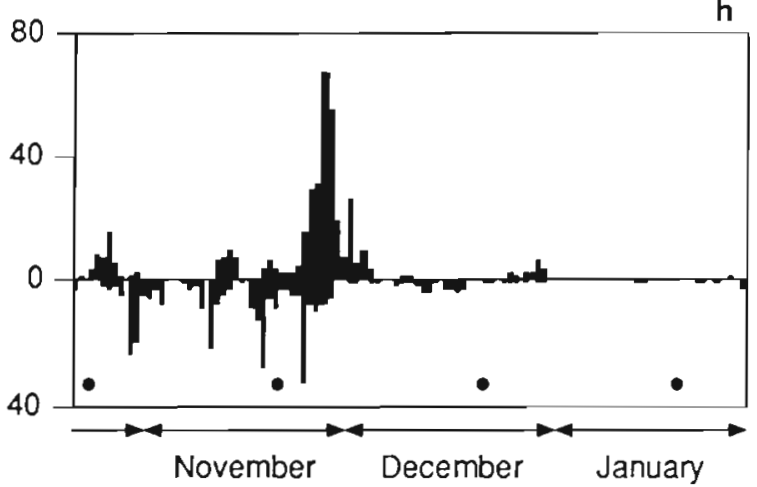

Fig. 5. Daily time series of larval supply in the front-reef (upper panels) and back-reef (lower panels) habitats for 8 taxa in the first season. Circles denote new moon periods. (a) Dischistodus spp.; (b) Pomacentrus coelestis; (c) other apogonids (d) Syngnathidae;

(e) Chromis atripectoralis; (f) Pomacentrus tripunctatus; (g) other blenniids; (h) Chrysiptera rollandi 
were collected in the back-reef habitat. However, over all 20 taxa, there was no determinable relationship between raw abundance in this habitat and the degree of synchrony $\left(r^{2}=0.13, p=0.118\right)$. The remaining 8 taxa showed no short-term lag effects and no significant cross-correlation in larval supply between habitats. This pattern can be explained for catches of Pomacentrus chrysurus, $P$. lepidogenys, $P$. tripunctatus, and Apogon sp1, by low numbers of larvae supplying the back-reef habitat during the major front-reef peak of the season (e.g. Fig. 5f). For Ecsenius sp. and other blenniids, this asynchrony appears to be effected mostly by a missing or low peak in the back-reef habitat during the first new moon (e.g. Fig. 5g). Larval supply in the pomacentrids, Abudefduf vaigiensis and Chrysiptera rollandi, appeared to be asynchronous between the 2 habitats throughout the season (e.g. Fig. 5h)

Results of the previous section have demonstrated a general increase in the relative magnitude of larval supply into the back-reef habitat during the second season of sampling. Patterns of coherence between the front-reef and back-reef habitats during this season were stronger by over $30 \%$ for 13 of the 20 taxa, with coherence in 7 of these taxa increasing from nonsignificant to r-values of 0.25 to 0.88 (Fig. 4). This increase in the synchrony of larval supply between habitats could not be simply attributed to an increase in resolving power through the addition of more fish to the back-reef habitat. There was no significant relationship between the absolute change in back-reef larval supply between the 2 seasons and any corresponding change in the synchrony coefficient, for any of the 13 taxa discussed above $\left(r^{2}=0.01, p=0.726\right)$. It appears that, for most taxa, there was a real change in the nature and strength of the larval supply relationship between the 2 habitats from one season to the next

For Pomacentrus chrysurus, $P$ tripunctatus, $P$. brachialis, $P$. lepidogenys and Apogon sp1, the dominant pulse of the year was much better represented in the back-reef habitat than in the previous season (e.g. Fig. 6a). For other apogonids, there was better coherence at the start of the season (Fig. 6b), while for pipefish (Syngnathidae), coherence increased as a result of higher back-reef catches during the December pulse (Fig. 6c). Larval supply in Dischistodus spp., P. coelestis and Amblypomacentrus breviceps showed no signs of the lag effect displayed the year before (e.g. Fig. 6d). In contrast to the previous year, larval supply of Ecsenius sp. and other blenniids was strong into the back-reef during the first new moon which almost certainly increased the synchrony coefficient between the 2 habitats (e.g. Fig. 6e). The reason for the increase in the degree of synchrony in larval supply of Chrysiptera rollandi is easily apparent from the raw plots (Fig. 6f), while for Chromis atripectoralis the increase appears to be due to a closer match in daily magnitude around the major peak of the season (Fig. $6 \mathrm{~g}$ ). Of the remaining taxa, 3 showed a negligible change $(<15 \%)$ in the synchrony of larval supply between the habitats, while in the last 4 synchrony declined between the years (Fig. 4)

The closer proximity of the lagoon to the front-reef habitat raises the question of whether larval supply into the lagoon was more synchronous to this habitat. Data from the final year of sampling suggest that this is true for $67 \%$ of the 18 taxa common enough in all 3 habitats to be analysed (Fig. 4). For these taxa, the synchrony between the front-reef and lagoon habitats was between 20 and $115 \%$ stronger than between the lagoon and the back-reef habitat (mean $=52.1, \mathrm{SE}=$ 8.22) (e.g. Fig. 7a). The opposite was true for only a minority of taxa and synchrony in larval supply of only one of these, Eviota sp., was more than $25 \%$ stronger between the back-reef habitat and the lagoon (Fig. 7b).

\section{DISCUSSION}

\section{Dynamics of larval supply}

At the habitat scale, patterns of larval supply were complex, with the magnitude and synchrony of pulses showing interactive effects across years. In the first year, larval supply was weakly synchronised across the front-reef and back-reef habitats for less than half of the 20 taxa analysed. For most taxa, low concordance in the magnitude of daily larval supply between the 2 habitats appeared to be driven by a sporadic lack of larvae supplying the back-reef habitat during the crucial new moon periods. Consistent with this observation is the greater magnitude of larvae that supplied the front-reef habitat over the entire season. Doherty (1987b) reported a similar gradient of abundance from a single month of sampling which suggests that this may be a predictable consistent pattern. However, in the second year of the present study, absolute levels of larval supply in the back-reef habitat were generally much higher, and the proportion of most taxa collected in this habitat relative to the front-reef habitat also increased. There was also a general increase in both the strength of the synchrony between the 2 habitats and in the number of taxa with significant correlation values. There was no evidence that this change was driven by an increase in resolving power of either the light traps or the analysis. This suggests that the gradient between the 2 habitats is systematic but variable across years. That this pattern occurred in a majority of taxa implies the existence of a broad-scale, inter- 

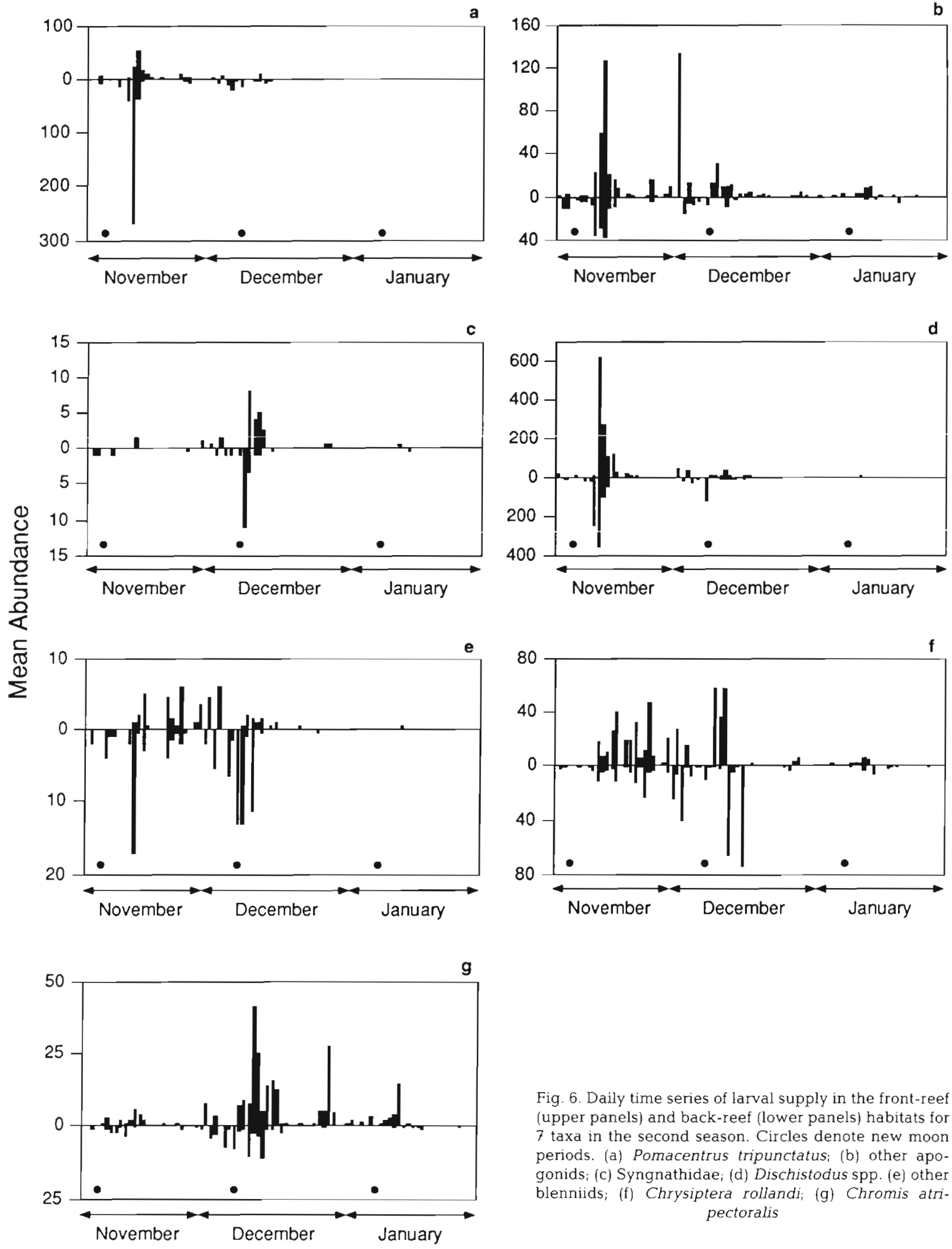

Fig. 6. Daily time series of larval supply in the front-reef (upper panels) and back-reef (lower panels) habitats for 7 taxa in the second season. Circles denote new moon periods. (a) Pomacentrus tripunctatus; (b) other apogonids; (c) Syngnathidae; (d) Dischistodus spp. (e) other blenniids; (f) Chrysiptera rollandi; (g) Chromis atripectoralis 
a

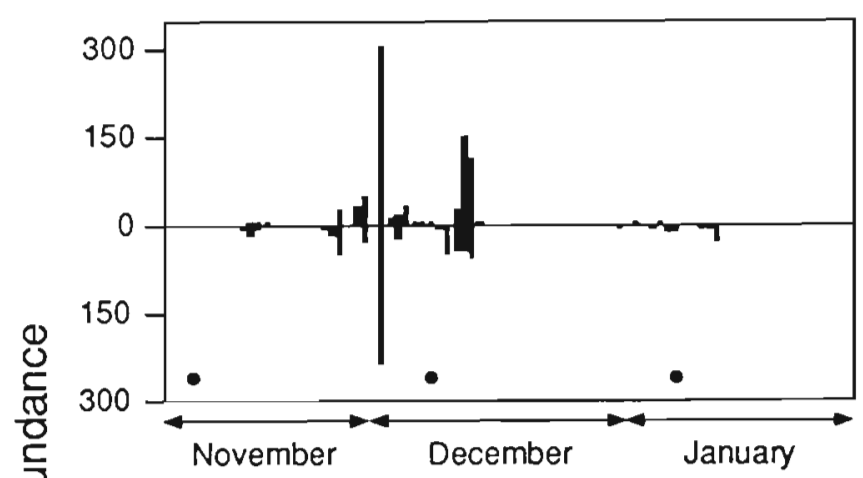

c

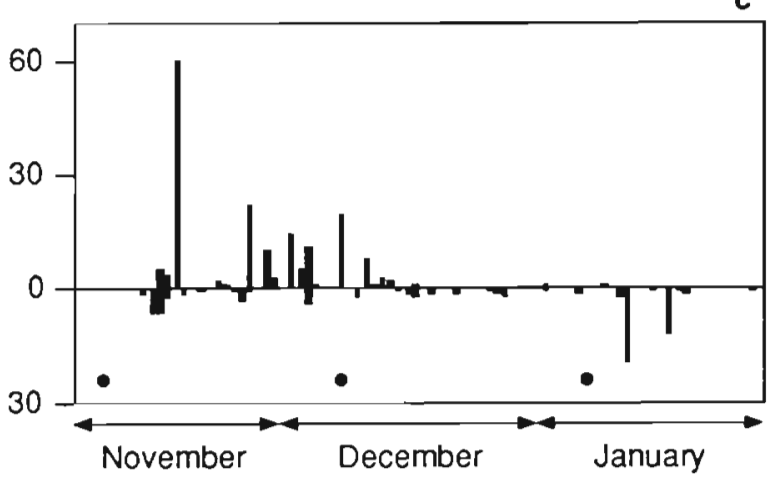

b
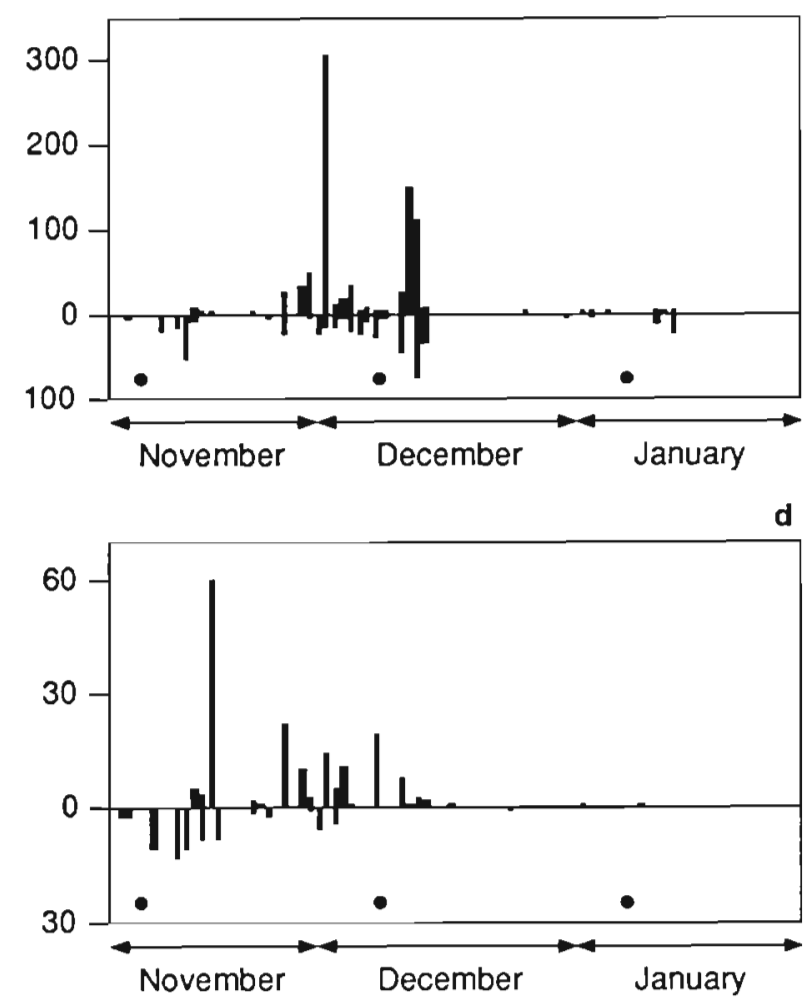

Fig. 7. Daily time series of larval supply in the lagoon (upper panels), or front-reef and back-reef (lower panels) habitats for 2 taxa in the second season. Circles denote new moon periods. Pomacentrus amboinensis: (a) lagoon and front-reef; (b) lagoon and back-reef. Eviota sp.: (c) lagoon and front-reef; (d) lagoon and back-reef

annual change in the nature of the replenishment process into the back-reef habitat.

Perhaps the simplest explanation for these patterns in larval supply concerns the amount of water that flows past each habitat during a particular recruitment season; an increase in larval supply to the back-reef habitat between years may be explainable by a concomitant increase in water flow to that habitat. Nontidal currents in the Lizard Island region are primarily wind-driven (Wolanski \& Ruddick 1981, Frith et al. 1986). Assuming the water flow hypothesis to be true, one would predict that as the front-reef and back-reef habitats oppose one another, any increase in back-reef catches should be matched by a decrease in front-reef catches. However, the observed inter-annual increase in back-reef abundance was not matched by a similar decrease in larval supply into the front-reef side. In fact, replenishment of two-thirds of the taxa showed some increase into this latter habitat between years. This implies that the replenishment process to Lizard Island is far more complex than this simple hypothesis allows. We suggest that understanding intra-reef patterns in larval supply requires careful consideration of interactions between hydrodynamics and factors such as reef topography (Alldredge \& Hamner 1980, Wolanski \& Hamner 1988, Kingsford et al. 1991). The interac- tion of wind and current flow with reef topography and its effect on inter-habitat patterns in larval supply is more fully explored in a companion study presented in this issue (Milicich 1994).

The only study comparable to the present one did not measure larval supply directly but focused on the distribution patterns of new recruits. Sale et al. (1984) described recruitment density of 4 species of coral reef fishes that settled to both the lagoon and front-reef habitat of 7 neighbouring reefs in the southern section of the GBR. Although the authors emphasised recruitment variability among reefs, we have re-analysed the data from their Table 6 using a paired-sample $t$-test to compare differences between the habitats, across all reefs, for each taxa. For the 2 pomacentrid species (Pomacentrus wardi and $P$. moluccensis), numbers in the lagoon of all reefs were consistently higher than in the front-reef habitat $(p=0.03$ and $p=0.02)$. The difference between habitats for Thalassoma lunare and Labroides dimidiatus was not significant, although this was only just so for the former species at the $95 \%$ significance level ( $p=0.06$ and $p=0.11$ ). These differences may have been caused by variations in the abundance of attractive settlement substrate (see also Williams \& Sale 1981), however the similar results of the present study show that it is, as they themselves 
suggested, more likely a function of systematic differences in larval supply.

Here we have emphasised the systematic nature of larval supply that can occur within the confines of a single reef. In contrast, settlement studies have emphasised the apparently 'stochastic' nature of larval supply to different local sites within a single reef (e.g. Williams \& Sale 1981, Victor 1986, Doherty 1987b). Apart from this local scale, most settlement studies have focused on events occurring at inter-reef scales. Observations of synchronicity in settlement among reefs separated by tens of kilometres has led to the hypothesis that neighbouring reefs are swept by a coherent, organised larval patch (Victor 1984, 1986, Doherty $1987 \mathrm{~b}$ ). Within this large co-ordinated patch, smaller, 'stochastic' patches are said to exist and replenishment of individual parts of a reef is hypothesised to occur via random collision between these paiches and suitable habitat.

The detection of multi-specific patches of reef fish larvae in inter-reef waters lends some credence to the existence of meso-scale larval patches (Williams \& English 1992, Thoriold 1993), however the presence of these patches says little about how larvae may be arranged as they approach the complex waters around reefs (Thorrold 1993). Analysis of patch size among replicate light traps within a habitat suggests that larvae are indeed organised into small (tens of metres) patches as they approach benthic habitats (Milicich 1992). However, the systematic differences in larval supply we recorded between the front-reef and backreef habitats suggest that at this scale, replenishment does not simply result from the stochastic collision of larval parcels with patches of habitat. The temporally variable nature of this process adds a further layer of complexity but does not detract from the consistency of patterns across a range of taxa. In the light of these developments it appears that the larval patch hypothesis must be re-evaluated. As Doherty (1987b) has pointed out, the primary motivation for constructing the hypothesis was to stimulate studies like the present one. Given the deliberately simple nature of the model that is imposed by the use of inferential data (Milicich 1988, Milicich et al. 1992), this re-appraisal can hardly be considered surprising. However, the recent and growing increase in the number of studies focusing on larval supply (Victor 1986, Doherty 1987a, Dufour 1991, McCormick \& Milicich 1993, Shenker et al. 1993, Milicich 1994, unpubl.) suggest that any such reassessment may be timely.

As an alternative hypothesis, synchrony may be caused by the simultaneous arrival of similarly aged larvae that have been produced by a regular, synchronous spawning cycle (Doherty 1991, Kingsford et al. 1991). Instead of a coordinated movement of a larval patch, replenishment may result from independent, albeit similarly timed events. Results of this study suggest that progress in understanding replenishment variability may be profitably made by focusing on the interaction of small groups of larvae with the local physical conditions surrounding each reef. Even if larval patches do exist in inter-reef water and are swept towards reefs, events occurring at the open water-reef interface appear to have an over-riding effect. Much of the systematic element of larval supply may be revealed by processes operating at this interface. This does not rule out the importance of survival and dispersal of the larval phase in determining final recruitment levels, it just suggests that local patterns in replenishment may be highly dependant on events occurring at the reef-open water interface.

Of course, the underlying rationale for studying replenishment variability is to understand fluctuations in benthic populations. Given this precis, how can focused studies of replenishment within a single reef be reconciled with the need to apply this data to a scale that is meaningful for the benthic population? Fortunateiy, this potentiai conflict in scale is seldom realised for coral reef fish populations. Once settled, the majority of coral reef fish are relatively sedentary (Sale 1978, Doherty \& Williams 1988), and are highly unlikely to move the distances required to travel from the frontreef side of Lizard Island to the back-reef side, or vice versa. They may change the type of substrate they occupy ontogenetically (Shulman \& Ogden 1987. Booth 1992), but even in these cases, the migration distances are often not great. This fidelity of fish to their initial settlement area suggests that differences in the number of larvae supplying parts of a single reef may have a large impact on the dynamics of older, benthic populations.

\section{Behaviour and depletion effects}

A minonty of taxa exhibited no change in habitatspecific catches between years, indicating consistent differences in the distribution of certain fish between the 2 habitats. Consistent low numbers of larvae of 3 taxa in back-reef traps (the pomacentrids, Chromis atripectoralis and Pomacentrus coelestis, and an apogonid, Apogon sp1) suggests that there may be a behavioural component to this pattern. A similar pattern of asynchrony was found by Leis (1986) and Leis \& Goldman (1987). Their study was largely restricted to small pre-flexion larvae, however their data suggested that certain taxa may be differentially distributed between the 2 sides of the island. They also suggested that there may be an entrainment mechanism operating off the front-side of the Island. If true, this may 
explain the consistently low numbers of the small pomacentrids (about halfway through their development) on the back-reef side.

The addition of the lagoon catches to the second season of the inter-habitat comparison revealed that these catches were more strongly synchronised to the frontreef habitat than to patterns in the back-reef habitat. In addition, for 10 taxa, total lagoon catch was less than half that of front-reef or back-reef catches. As the lagoon at Lizard Island is very close to the front-reef sites (see Fig. 1), one might expect that larval supply into the lagoon will be progressively depleted as fish that aggregate beyond the reef margin cross the reef flat and start to settle. Alternatively, this trend could be due to methodological bias; lagoon waters are more turbid and this may have impaired the abilities of fish to see the light traps and respond. We feel this is highly unlikely since settlement patterns of 3 species of pomacentrid in this habitat showed similar patterns to those determined from the light traps (Milicich et al. 1992).

Although depletion may explain some of these observed patterns, numbers of larvae in the lagoon for several other taxa were so low or high that active choice seems to be involved. Lagoon preferences were shown by 3 taxa, the schooling pelagics, eviotid gobies and 1 species of apogonid. Catches of a further 4 taxa were so low (seasonal sum less than 10 for Pomatocentrus coelestus, Lethrinidae, $P$. lepidogenys and Neopomacentrus spp.) that there is a strong suggestion of an active behavioural component. Pitcher (1987) described a similar pattern of lagoon 'avoidance' in settlement for a species common to this study ( $P$. nagasakiensis) at both Lizard Island and Heron Reef (in the Capricorn/Bunker section of the GBR). The reason for these patterns are unclear, yet evidence from work on settled fish distributions suggests that preferences for certain sites may be widespread (Sale \& Williams 1981). Most fish appear to settle at night (Victor 1991), and this has resulted in an emphasis on cues, other than visual ones, in determining the choice of settlement at small spatial scales (between colonies; Sweatman 1983, 1985). This study presents the first direct evidence to suggest that some fish are capable of discerning among habitats prior to nightly settlement. Visual cues may be important to this process and lagoon 'avoidance' may be driven by discrimination of turbidity or turbulence gradients.

\section{Summary}

Collectively, the evidence presented here suggests that larval supply at the habitat level is systematic (albeit highly variable between years), yet dynamically independent. This theme is explored more fully in the companion paper presented in this volume, however, it serves to stress the fact that the supply of larvae to reef habitats is a complex process that may be best approached by focusing on local interactions between the reef, the open water surrounding it and the larvae themselves. Clearly competent reef fish larvae are capable of making behavioural choices and these cannot be ignored in any replenishment study.

The results of this study illustrate the difficulty of inferring larval distributions from static settlement patterns. Although undeniably useful, predictions from these studies have been necessarily simple (e.g. Victor 1984, Williams 1986, Pitcher 1987, Doherty 1991) and are unable to discern the detail that is necessary to determine how, when and where larvae replenish benthic habitats. The pelagic environment is highly plastic and heterogenous and we can only hope to understand the link between this environment, the reef and the life of pre-settlement fish by sampling it directly.

Acknowledgements. Invaluable comments on the original thesis version of this manuscript were made by $P$. Sale, $M$. Sinclair and I. Suthers. Four anonymous reviewers made many useful suggestions and comments. This work was conducted while M.J.M. was a holder of a Postgraduate Scholarship from Griffith University and a Lizard Island Postgraduate Fellowship from the Australian Museum. Further funding was made available by awards from The Australian Coral Reef Society, The Great Barrier Reef Marine Park Authority and the Fishing Industry Research and Development Council. Many people helped in the field; thanks to J. Davidson, P. Dempsey, D. Grice, M. McCormick, L. McIlwain, K. Milicich, A. Page, A. Rogers, Rowena, Bob and L. Whiteley. We also acknowledge the support of the Australian Institute of Marine Science and J. Shenker of the Florida Institute of Technology who made space and facilities available to M.J.M. during the final stages of manuscript preparation.

\section{LITERATURE CITED}

Alldredge, A. L., Hamner, W. M. (1980). Recurring aggregation of zooplankton by a tidal current. Estuar. coast. mar. Sci. 10: $31-38$

Booth, D. J. (1992). Larval settlement patterns and preferences by domino damselfish Dascyllus albisella Gill. J. exp. mar. Biol. Ecol. 155: 85-104

Choat, J. H., Doherty, P. J., Kerrigan, B. A., Leis, J. M. (1993). Larvae and pelagic young of coral reef fishes: comparison of three towed nets, a purse seine and two light aggregation devices. Fish. Bull. U.S. 91: 159-209

Cushing, D. H. (1982). Climate and fisheries. Academic Press, New York

Daan, N., Bromley, P. J., Hislop, J. R. G., Nielson, N. A. (1990). Ecology of North Sea fish. Neth. J. Sea Res. 26: 343-386

Doherty, P. J. (1987a). Light traps: selective but useful devices for quantifying the distributions and abundances of larval fishes. Bull. mar. Sci. 41: 423-431

Doherty, P. J. (1987b). The replenishment of populations of coral reef fishes, recruitment surveys, and the problems of variability manifest on multiple scales. Bull. mar. Sci. 41 : $411-422$ 
Doherty, P. J. (1991). Spatial and temporal patterns in recruitment. In: Sale, P. F. (ed.). The ecology of fishes on coral reefs. Academic Press, San Diego, p. 261-293

Doherty, P. J., Fowler, A. J. (1993). An empirical test of recruitment limitation in a coral reef fish on the Great Barrier Reef. Science 263: 935-939

Doherty, P. J., Williams, D. McB.(1988). The replenishment of coral reef populations. Oceanogr. mar. Biol. A. Rev. 26: $487-551$

Dufour, V. (1991). Variations of fish larvae abundance in reefs. effect of light on the colonisation of the reefs by fish larvae. C.r. Acad. Sci. Paris 313: 187-194

Faber, D. J. (1981). A light trap to sample littoral and limnetic regions of lakes. Verh. int. Verein Limnol. 21: 776-781

Frith, C. A., Leis, J. M., Goldman, B. (1986). Currents in the Lizard Island region of the Great Barrier Reef and their relevance to potential movements of larvae. Coral Reefs 5: $81-92$

Jones, G. P. (1987). Competitive interactions between residents and recruits in two coral reef fishes. J. exp. mar. Biol. Ecol. 68: 1534-1547

Kingsford, M. J. (1990). Linear oceanographic features: a focus for research on recruitment processes. Aust. J. Ecol. 15: $391-401$

Kingsford, M. J., Wolanski, E., Choat, J. H. (1991). Influence of tidally-induced fronts and Langmuir circulations on the distribution and movements of presettlement fishes around a coral seé. Mîar. Biol. 109: 167-180

Kuznetsov, S., Khalileev, A. (1991). Mesosaur time series: a companion to SYSTAT. SYSTAT, Inc., Evanston, IL

Lasker, R. (1981). The role of a stable ocean in larval fish survival and subsequent recruitment. In: Lasker, R. (ed.) Marine fish larvae: morphology, ecology and relation to fisheries. Univ. of Washington Press, Seattle, p. 80-87

Leis, J. M. (1986). Vertical and horizontal distributions of fish larvae near coral reefs at Lizard Island, Great Barrier Reef. Mar. Biol. 90: 505-516

Leis, J. M. (1991). The pelagic stage of reef fishes: the larval biology of coral reef fishes. In: Sale, P. F. (ed.) The ecology of fishes on coral reefs. Academic Press, San Diego, p. $183-230$

Leis, J. M., Goldman, B. (1987). Composition and distribution of larval fish assemblages in the Great Barrier Reef lagoon, near Lizard Island, Australia. Aust. J. mar. Freshwat. Res. 38: 211-223

McCormick, M. I., Milicich, M. J. (1993). Late pelagic-stage goatfishes: distribution patterns and inferences on schooling behaviour. J. exp. mar. Biol. Ecol. 174: 15-42

Meekan, M. G., Milicich, M. J., Doherty, P. J. (1993). Spawning determines temporal patterns of replenishment in a coral reef fish. Mar. Ecol. Prog. Ser. 93: 217-225

Milicich, M. J. (1988). The distribution and abundance of presettlement fish in the nearshore waters of Lizard Island Proc. 6th int. coral Reef Symp. 2: 785-790

Milicich, M. J. (1992). Light traps: a novel technique for monitoring larval supply and replenishment of coral reef fish populations. Ph.D. thesis, Griffith University, Brisbane

Milicich, M. J. (1994). Dynamic coupling of reef fish replenishment and oceanographic processes. Mar. Ecol. Prog. Ser. 110: 135-144

Milicich, M. J., Meekan, M. G., Doherty, P. J. (1992). Larval supply: a good predictor of recruitment of three species of reef fish (Pomacentndae). Mar. Ecol. Prog. Ser. 86: $153-166$

This article was presented by D. Alongi (Senior Editorial Advisor), Townsville, Australia
Pitcher, C. R. (1987). Validation and application of otolith ageing techniques to some problems in the ecology of coral reef fishes. Ph.D dissertation, Griffith University, Brisbane

Robertson, D. R., Green, D. G., Victor, B. C. (1988). Temporal coupling of reproduction and recruitment of larvae of a Caribbean reef fish. Ecology 69: 370-381

Rothschild, B. J. (1986). Dynamics of marine fish populations Harvard Univ. Press, Cambridge

Sale, P. F. (1978). Coexistence of coral reef fishes - a lottery for living space. Environ. Biol. Fish. 3: 85-102

Sale, P. F., Doherty, P. J., Eckert, G. J., Douglas, W. A., Ferrell D. J. (1984). Large scale spatial and temporal variation in recruitment to fish populations on coral reefs. Oecologia 64: $191-198$

Shenker, J. M., Maddox, E., Wishinski, E., Pearl, S., Thorrold, S., Smith, N. (1993). Onshore transport of settlement-stage Nassau grouper Epinephelus striatus and other fishes in Exuma Sound, Bahamas. Mar. Ecol. Prog. Ser. 98: 31-43

Shulman, M. J., Ogden, J. C. (1987). What controls tropical reef fish populations: recruitment or benthic mortality? An example in the Caribbean reef fish Haemulon flavolineatum. Mar. Ecol. Prog. Ser. 39: 233-242

Sweatman, H. P. A. (1983). Influence of conspecifics on choice of settlement sites by larvae of two pomacentrid fishes (Dascyllus aruanus and D. reticulatus) on coral reefs. Mar. Biol. 75: 225-229

Sweatman, H. P. A. (1985). The influence of adults of some corai reef fishes on larval recruitment. Ecol. Monogr. 55: 469-485

Thorrold, S. R. (1993). Coupling of hydrography and pre-settlement reef fish distributions in the central Great Barrier Reef lagoon. Proc. 7 th int. coral Reef Symp. (in press)

Thorrold, S. R., Milicich, M. J. (1990). Comparison of larval duration and pre- and post-settlement growth in two species of damselfish, Chromis atripectoralis and Pomacentrus coelestis (Pisces: Pomacentridae), from the Great Barrier Reef. Mar. Biol, 105: 375-384

Victor, B. C. (1984). Coral reef fish larvae: patch size estimation and mixing in the plankton. Limnol. Oceanogr. 29: $1116-1119$

Victor, B. C. (1986). Larval settlement and juvenile mortality in a recruitment-limited coral reef fish population. Ecol. Monogr. 56: 145-160

Victor, B. C. (1991). Settlement strategies and biogeography of reef fishes. In: Sale, P. F. (ed.) The ecology of fishes on coral reefs. Academic Press, San Diego, p. 231-260

Williams, D. McB. (1986). Spatial and temporal scales of processes determining inter-annual variation in recruitment of fishes of the Great Barrier Reef: some preliminary data. International Oceanographic Commission Workshop Report 44 (supplement), Manila, p. 229-239

Williams, D. McB., English, S. (1992). Distribution of fish larvae around a coral reef: direct detection of a meso-scale, multi-specific patch? Cont. Shelf Res. 12: 923-927

Williams, D. McB., Sale, P. F. (1981). Spatial and temporal patterns of recruitment of juvenile coral reef fishes to coral habitats within 'One Tree Lagoon', Great Barrier Reef. Mar. Biol. 65: 245-253

Wolanski, E., Hamner, W. M. (1988). Topographically controlled fronts in the ocean and their biological significance. Science 241: 177-181

Wolanski, E., Ruddick, B. (1981). Water circulation and shelf waves in the northern Great Barrier Reef Lagoon. Aust. J. mar. Freshwat. Res. 32: 721-740 